Check for updates

Cite this: RSC Adv., 2019, 9, 21804

Received 24th April 2019

Accepted 6th July 2019

DOI: 10.1039/c9ra03035b

rsc.li/rsc-advances

\title{
Deep oxidative desulfurization of model fuels catalysed by immobilized ionic liquid on MIL- 100(Fe)
}

\begin{abstract}
WanXin Yang, Guoqing Guo, Zhihong Mei and Yinghao Yu (DD *
Deep desulfurization of fossil fuels has become urgently required because of the serious pollution by the large-scale use of fossil fuels. In this study, $\left[\mathrm{PrSO}_{3} \mathrm{HMIm}_{\mathrm{HSO}}\right.$ (aMIL-100(Fe) was synthesized by wetimpregnation of the ionic liquid (IL) of $\left[\mathrm{PrSO}_{3} \mathrm{HMIm}_{\mathrm{HSO}} \mathrm{HS}_{4}\right.$ on $\mathrm{MIL}-100$ (Fe). The construction of $\left[\mathrm{PrSO}_{3} \mathrm{HMIm}\right] \mathrm{HSO}_{4} \mathrm{QMIL-100}(\mathrm{Fe})$ was then confirmed by $\mathrm{X}$-ray powder diffraction, $\mathrm{N}_{2}$ adsorptiondesorption experiments, infrared spectroscopy and elemental analysis, and then applied in the oxidative desulfurization of model fuels. In comparison with the corresponding IL, [PrSO $\mathrm{HMIm}_{3} \mathrm{HSO}_{4} @ \mathrm{MIL}-$ 100 (Fe) showed an enhanced performance in the desulfurization rate of model fuels due to the increase of the mass transfer rate. Under the optimized conditions (oxidant to sulphur ratio $=25$, oil to acetonitrile ratio $=1$, and temperature $=60^{\circ} \mathrm{C}$ ), a sulphur removal rate of $99.3 \%$ was observed (initial sulphur concentration $=50 \mathrm{ppm}$ ). The sulphur removal of three sulphur compounds by catalytic oxidation and extraction followed the order of dibenzothiophene (DBT) > thiophene (T) > benzothiophene (BT).
\end{abstract}

\section{Introduction}

The rapid development of the automotive industry has greatly exacerbated the use of fossil fuels..$^{1-5}$ After combustion, the organic compounds in gasoline are converted to carbon oxides (COx), nitrogen oxides (NOx) and sulphur oxides (SOx), among which, sulphur oxides are one of the important reasons for haze and acid rain..$^{6-9}$ Sulphide emissions from burning gasoline can cause harm to the human lungs and respiratory system, resulting in throat spasms and suffocation. ${ }^{10}$ Currently, the sulphur content in gasoline in China must be from $50 \mu \mathrm{g} \mathrm{g}^{-1}$ to $10 \mu \mathrm{g} \mathrm{g}^{-1}$ according to the National standard of gasoline for motor vehicles (GB17930-2013 and GB17930-2016). Above all, it is necessary to reduce the sulphur content of gasoline and reduce the emission of sulphur oxides into the atmosphere. ${ }^{11-13}$

The oxidative desulfurization (ODS) technology has many advantages such as mild reaction conditions, ${ }^{\mathbf{1 4}}$ high desulfurization rate, simple process and low equipment investment, compared with traditional hydrodesulfurization methods. ODS has been widely used for the development of ultra-low sulphur products. ${ }^{15,16}$ The catalysts used for oxidative desulfurization are very critical. In recent years, IL catalysts has been used in the oxidative desulfurization reaction in gasoline..$^{17-19}$ However, although these IL catalysts are efficient in desulfurization, the ILs cannot be directly separated and recovered because they are easily dissolved in extracting agents, such as acetonitrile, ${ }^{20}$ which is not conducive to industrialization. In

School of Chemistry and Chemical Engineering, South China University of Technology, Guangzhou 510641, China.E-mail: ceyhyu@scut.edu.cn

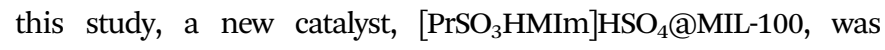
synthesized by wet impregnation. The effect of several important factors, including the loading amount, reaction temperature, desulfurization system, catalyst dosage, and the recycling of catalyst, on the desulfurization efficiency was studied.

\section{Experimental}

\subsection{Materials}

Iron(III) chloride hexahydrate $\left(\mathrm{FeCl}_{3} \cdot 6 \mathrm{H}_{2} \mathrm{O}\right)$ and ethanol were obtained from Damao Chemical Reagent Factory. Acetonitrile, $n$-octane, 1,3,5-benzenetricarboxylic acid ( $\left.\mathrm{H}_{3} \mathrm{BTC}\right)$, thiophene (T), benzothiophenen (BT) and dibenzothiophene (DBT) were purchased from J\&K Scientific Ltd. 1-Sulfopropyl-3-methylimidazolium hydrosulphate ([ $\left.\left.\mathrm{PrSO}_{3} \mathrm{HMIm}\right] \mathrm{HSO}_{4}\right)$ was obtained from Lanzhou Greenchem ILs. All solvents and reagents were used as received without further purification.

\subsection{Synthesis of MIL-100(Fe)}

MIL-100(Fe) was synthesized according to the previous report under the following methods. ${ }^{21,22}$ A mixture of $\mathrm{FeCl}_{3} \cdot 6 \mathrm{H}_{2} \mathrm{O}$ $(0.010 \mathrm{~mol}, 2.70 \mathrm{~g})$ and BTC (0.066 mol, $1.39 \mathrm{~g})$ was dispersed in $50 \mathrm{~mL}$ distilled water under weak sonication and was then reacted for $72 \mathrm{~h}$ at $130{ }^{\circ} \mathrm{C}$ in a Teflon lined autoclave. After being cooled down to room temperature, the light orange solid product was further purified by centrifugation at $6000 \mathrm{rpm}$ for $10 \mathrm{~min}$ with ethanol $(50 \mathrm{~mL} \times 3)$. Then the highly purified solid was dried under vacuum at $60{ }^{\circ} \mathrm{C}$ overnight. 


\subsection{Synthesis of $\left[\mathrm{PrSO}_{3} \mathrm{HMIm}\right] \mathrm{HSO}_{4} @ \mathrm{MIL}-100(\mathrm{Fe})$}

$\left[\mathrm{PrSO}_{3} \mathrm{HMIm}\right] \mathrm{HSO}_{4} @ M I L-100(\mathrm{Fe})$ was prepared by wet impregnation. ${ }^{23,24}$ A certain amount of anhydrous $\left[\mathrm{PrSO}_{3} \mathrm{HMIm} \mathrm{HSO}_{4}\right.$ was dissolved in $50 \mathrm{~mL}$ ethanol. After complete dissolution, $15 \mathrm{~g}$ activated MIL-100(Fe) was added to the solution and subjected to continuous magnetic stirring for $24 \mathrm{~h}$. Then, filtration was employed to remove the redundant solvent, followed by drying in vacuum at $80{ }^{\circ} \mathrm{C}$ overnight. The orange powder product was donated as $X$-[ $\left.\mathrm{PrSO}_{3} \mathrm{HMIm}\right] \mathrm{HSO}_{4} @ \mathrm{MIL}-100\left(X \mathrm{mmol} \mathrm{g}^{-1}\left[\mathrm{PrSO}_{3}{ }^{-}\right.\right.$ HMIm] $\left.\mathrm{HSO}_{4} @ M I L-100\right)$, where $X$ means the adding amount of $\left[\mathrm{PrSO}_{3} \mathrm{HMIm}\right] \mathrm{HSO}_{4}$ in the solution $(X=0.7,0.9,1.1,1.3,1.5)$.

\subsection{Desulfurization}

Dibenzothiophene (0.05 g, DBT) was completely dissolved into $n$ octane to prepare model oil with the sulphur content of $50 \mathrm{ppm}$. Similarly, the model oils with different sulphur compounds, including thiophene and benzothiophenen, was prepared. The catalyst, acetonitrile and $10 \mathrm{~mL}$ model oil were added into a flask. Then the flask was in an oil bath at the desired temperature and stirred for 15 min. $\mathrm{H}_{2} \mathrm{O}_{2}$ was injected into the flask. After the start of the reaction, the stirring was stopped at regular intervals, the samples from the upper oil phase were withdrawn and filtered with an organic filter, then sulphur content in the samples were determined by the WK-2D micro-coulometer (Jiangfen Electroanalytical instrument Co., Ltd, China, detection limit: $0.1 \mathrm{ng} \mathrm{mL}^{-1}$ ). And the conversion rate of the sulphur was calculated according to eqn (1):

$$
R_{0}=\frac{C_{0}-C_{\mathrm{e}}}{C_{0}} \times 100 \%
$$

where, $R$ is the desulfurization rate, $C_{0}$ is the initial sulphur content of the oil, and $C_{\mathrm{e}}$ is the sulphur content of the oil after desulfurization.

\subsection{Characterization}

X-Ray Diffraction (XRD) patterns were collected with a Bruker D8 ADVANCE diffractometer using $\mathrm{Cu} \mathrm{K} \alpha$ radiation at a scanning rate of $1^{\circ} \min ^{-1}$ between $5^{\circ}$ and $40^{\circ}$. Infrared spectra were recorded in $\mathrm{KBr}$ discs with a Bruker Fourier-transform infrared (FT-IR) spectrometer. The specific surface areas and pore size distributions were obtained from $\mathrm{N}_{2}$ adsorption-desorption isotherms measured on a Micromeritics ASAP-2010 instrument at $-196{ }^{\circ} \mathrm{C}$. The contents of $\mathrm{C}, \mathrm{H}, \mathrm{N}$, and $\mathrm{S}$ in the composite material were measured using Elementar's Vario EL III elemental analyzer.

\section{Results and discussion}

\subsection{X-ray diffraction (XRD) analysis}

The powder XRD patterns of the virgin MOFs and a series of ILs@MOF are exhibited in Fig. 1. These diffraction patterns agreed with those reported in the literature..$^{25-29}$ The peak at $10.9^{\circ}$ indicated that the pattern corresponded to the reported MIL-100(Fe). The XRD patterns of the ILs@MIL-100(Fe) materials were similar to that of the parent material MIL-100(Fe), which indicated that the crystal structure of MIL-100(Fe) was preserved after the incorporation of $\left[\mathrm{PrSO}_{3} \mathrm{HMIm}\right] \mathrm{HSO}_{4}$, and adding IL did not change the crystal form of MIL-100.

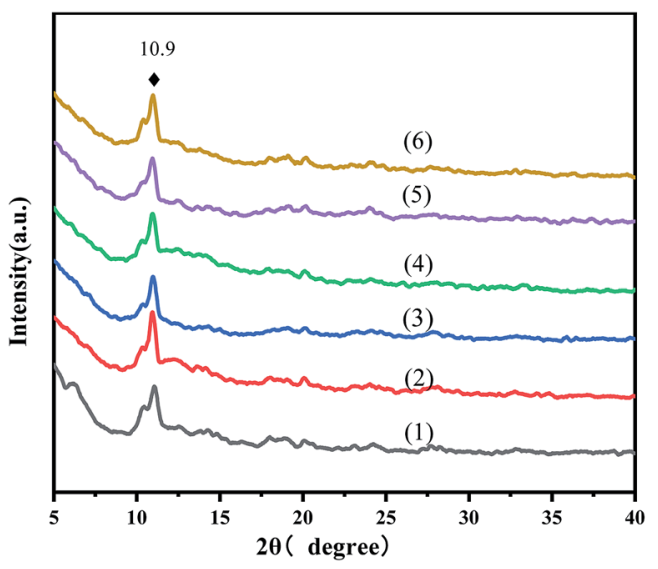

Fig. 1 XRD patterns of MIL-100(Fe) (1) and $X$-[PrSO $\mathrm{PMIm}_{3} \mathrm{HSO}_{4}$ (aMIL-100(Fe) $(2-6, X=0.7,0.9,1.1,1.3,1.5)$.

\subsection{Fourier transform infrared (FT-IR)}

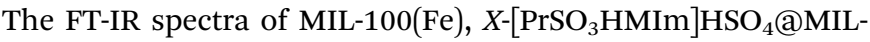
$100(\mathrm{Fe})$ and $\left[\mathrm{PrSO}_{3} \mathrm{HMIm}\right] \mathrm{HSO}_{4}$ were recorded in the spectral range of $4000-400 \mathrm{~cm}^{-1}$ (Fig. 2). The peaks of [ $\mathrm{PrSO}_{3} \mathrm{HMIm}$ ] $\mathrm{HSO}_{4}$ at 1224 and $1046 \mathrm{~cm}^{-1}$ were related to $\nu(\mathrm{O}=\mathrm{S})$ asymmetric and symmetric stretching vibrations of the sulfonic acid group. ${ }^{\text {20-22 }}$ The characteristic peaks of MIL-100(Fe) at 1714 and $1383 \mathrm{~cm}^{-1}$ attributed to $\nu(\mathrm{C}=\mathrm{O})$ stretching vibration and $\nu(\mathrm{C}-\mathrm{O})$ stretching vibration in the MIL-100(Fe) matrix could be observed..$^{22,30-32}$ The characteristic vibrational bands of the $\mathrm{C}=\mathrm{C}$ and $\mathrm{C}=\mathrm{N}$ group at 1573 and $1457 \mathrm{~cm}^{-1}$ were also observed corresponding to the imidazole ring. ${ }^{33,34}$ It was concluded that $\left[\mathrm{PrSO}_{3} \mathrm{HMIm}\right] \mathrm{HSO}_{4}$ was successfully supported on MIL-100(Fe).

\subsection{Elemental analysis}

The $\mathrm{S}$ and $\mathrm{N}$ elements of the $X$-[ $\left.\mathrm{PrSO}_{3} \mathrm{HMIm}\right] \mathrm{HSO}_{4} @ \mathrm{MIL}-$ $100(\mathrm{Fe})(X=0.7,0.9,1.1,1.3,1.5)$ composites were analysed to calculate the amount of IL in the hybrid materials. It could be seen from the Table 1 that the $\mathrm{S}$ and $\mathrm{N}$ elements in the hybrid material showed an increasing trend with the increase of the

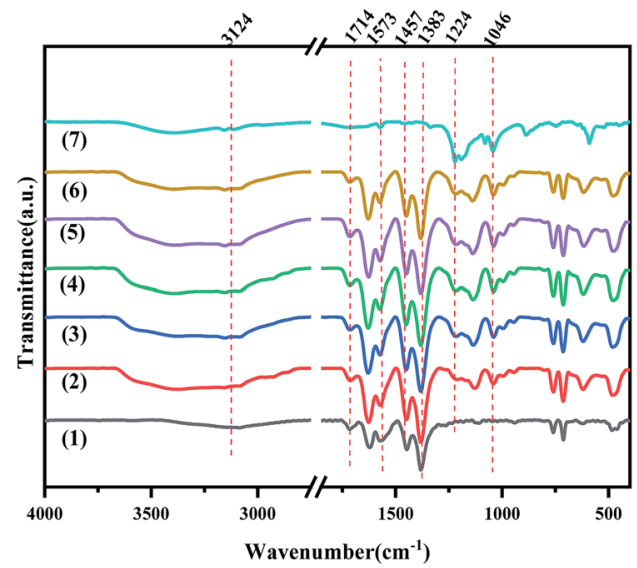

Fig. 2 The FT-IR spectra of MIL-100(Fe) (1), $X$-[PrSO $\mathrm{PHMIm}_{3} \mathrm{HSO}_{4}$ (aMIL-100(Fe) (2-6) $(X=0.7,0.9,1.1,1.3,1.5)$ and $\left[\mathrm{PrSO}_{3} \mathrm{HMIm}^{-} \mathrm{HSO}_{4}(7)\right.$. 
Table 1 Elemental analysis of MIL-100(Fe) and X-ILs@MIL-100(Fe)

\begin{tabular}{llll}
\hline Samples & $\mathrm{S}(\mathrm{wt} \%)$ & $\mathrm{N}(\mathrm{wt} \%)$ & $\begin{array}{l}\text { Actual loading } \\
\left(\mathrm{mmol} \mathrm{g}^{-1}\right)\end{array}$ \\
\hline MIL-100(Fe) & - & 1.019 & - \\
0.7-ILs@MIL-100(Fe) & 3.515 & 1.516 & 0.549 \\
0.9-ILs@MIL-100(Fe) & 3.990 & 1.642 & 0.623 \\
1.1-ILs@MIL-100(Fe) & 4.474 & 1.800 & 0.699 \\
1.3-ILs@MIL-100(Fe) & 4.921 & 1.940 & 0.769 \\
1.5-ILs@MIL-100(Fe) & 5.492 & 2.173 & 0.858
\end{tabular}

adding amount of IL, indicating that more IL groups were grafted into the pores of MIL-100(Fe) when more IL was added. The actual loading of $\left[\mathrm{PrSO}_{3} \mathrm{HMIm}\right] \mathrm{HSO}_{4}$ could be calculated by the percentage content of the $\mathrm{S}$ elements in the hybrid material. According to the results, it can be seen from Table 1 that there were some certain differences between the actual loading and the theoretical one, because a part of ionic liquids on the surface of the materials were washed away during the process of synthesizing the composite materials.

\section{4 $\mathrm{N}_{2}$ adsorption-desorption experiment}

Fig. 3 show $\mathrm{N}_{2}$ adsorption-desorption isotherms of MIL-100(Fe) and $X$-[ $\left.\mathrm{PrSO}_{3} \mathrm{HMIm}\right] \mathrm{HSO}_{4} @ M I L-100(\mathrm{Fe})$. The BET surface area and pore volume were obtained from nitrogen physisorption isotherms at $77 \mathrm{~K}$, and the results are given in Table 2 .

It could be seen that the $\mathrm{N}_{2}$ adsorption-desorption isotherms of the series of composites showed a type IV isotherms. There were also hysteresis loops, which were characteristic of mesoporous or microporous materials. In addition, the pore sizes of the samples were greater than $2 \mathrm{~nm}$, indicating that they were both mesoporous materials, and the structure of MIL-100(Fe) were not significantly altered by loading the ionic liquids by the impregnation method. The BET surface area and pore volume for the prepared MIL-100(Fe) was $1168.1 \mathrm{~m}^{2} \mathrm{~g}^{-1}$ and $0.74 \mathrm{~cm}^{3} \mathrm{~g}^{-1}$, respectively, close to the values reported in the literature. ${ }^{28,30}$ According to the results, the specific surface area and pore volume decreased after the impregnation process.

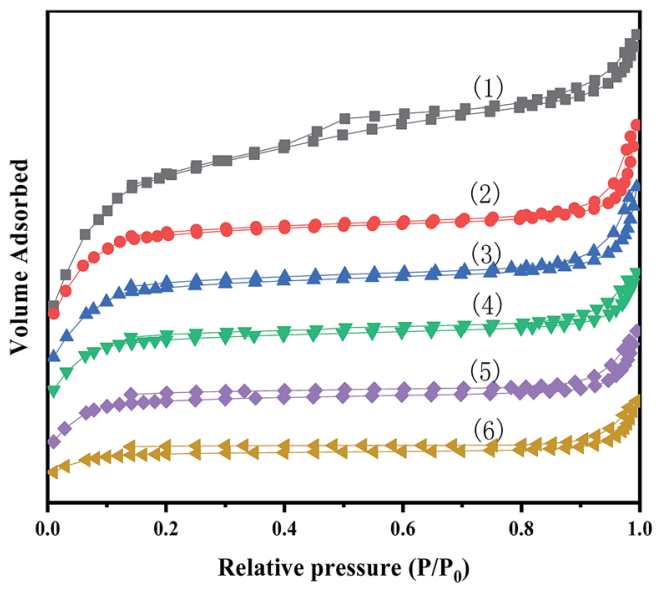

Fig. $3 \mathrm{~N}_{2}$ adsorption-desorption isotherms for MIL-100(Fe) (1) and $X$ $\left[\mathrm{PrSO}_{3} \mathrm{HMIm}_{\mathrm{HSO}} \mathrm{QMIL-100}(\mathrm{Fe})(2-6)(X=0.7,0.9,1.1,1.3,1.5)\right.$.
Table 2 Structural properties of MIL-100(Fe) and X-ILs@MIL-100(Fe) $(X=0.7,0.9,1.1,1.3,1.5)$ characterized by $N_{2}$ adsorption

\begin{tabular}{lll}
\hline Samples & $\begin{array}{l}\text { BET surface } \\
\text { area }\left(\mathrm{m}^{2} \mathrm{~g}^{-1}\right)\end{array}$ & $\begin{array}{l}\text { Pore volume } \\
\left(\mathrm{cm}^{3} \mathrm{~g}^{-1}\right)\end{array}$ \\
\hline MIL-100(Fe) & 1168.1 & 0.74 \\
0.7-ILs@MIL-100(Fe) & 785.6 & 0.47 \\
0.9-ILs@MIL-100(Fe) & 674.5 & 0.42 \\
1.1-ILs@MIL-100(Fe) & 525.7 & 0.33 \\
1.3-ILs@MIL-100(Fe) & 418.2 & 0.26 \\
1.5-ILs@MIL-100(Fe) & 170.0 & 0.13 \\
\hline
\end{tabular}

The decrease could be related to the pore blocking of the support by the attachment of ILs. ${ }^{35}$

\subsection{Catalytic activities for ODS}

3.5.1 Effects of time and loading amount on oxidative desulfurization. The ILs loading amount had a significant effect on the reaction. It was evident from Fig. 4 that ODS was catalysed by various catalysts. The desulfurization efficiency of the $\left[\mathrm{PrSO}_{3} \mathrm{HMIm}\right] \mathrm{HSO}_{4} @ M I L-100(\mathrm{Fe})$ systems was higher than that of the virgin MIL-100(Fe) and $\left[\mathrm{PrSO}_{3} \mathrm{HMIm}\right] \mathrm{HSO}_{4}$ under the same catalysis conditions. The activity was improved by increasing the contents of $\left[\mathrm{PrSO}_{3} \mathrm{HMIm}\right] \mathrm{HSO}_{4}$ in the $\left[\mathrm{PrSO}_{3}\right.$ HMIm] $] \mathrm{HSO}_{4} @ M I L-100(\mathrm{Fe})$ system from 0.7 to $1.1 \mathrm{mmol} \mathrm{g}^{-1}$,

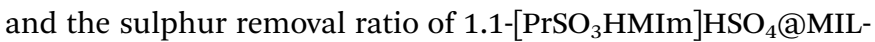
$100(\mathrm{Fe})$ reached $99.31 \%$, showing a beneficial effect of $\left[\mathrm{PrSO}_{3}-\right.$ $\mathrm{HMIm}] \mathrm{HSO}_{4}$ during the catalysis. However, the sulphur removal of 1.3-ILs@MIL-100(Fe) and 1.5-ILs@MIL-100(Fe) was lower than that of 1.1-ILs@MIL-100(Fe). We speculated that the increased acid ion loading resulted in a reduced MIL-100(Fe) pore volume and reaction specific surface area, which reduced the mass transfer efficiency. ${ }^{36,37}$ Thus, the loading amount of $1.1 \mathrm{mmol} \mathrm{g}^{-1}$ and the optimal time of $180 \mathrm{~min}$ were proper for the following investigation, respectively.

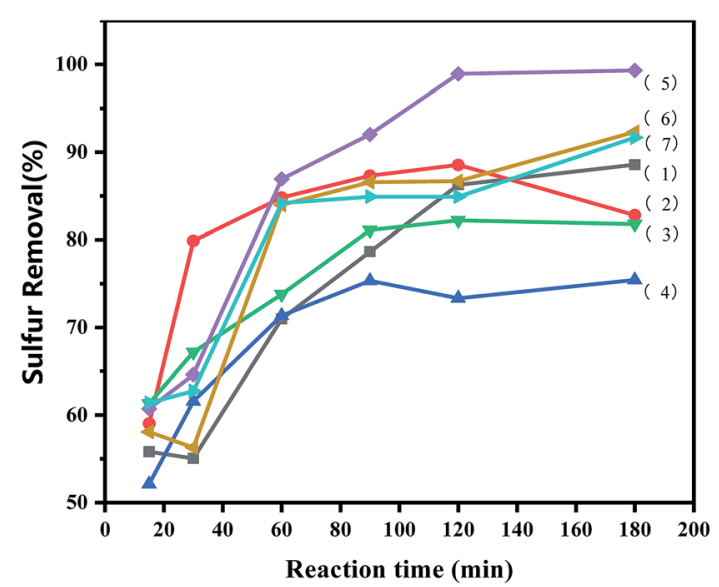

Fig. 4 Effects of reaction time and loading amount of IL on oxidative desulfurization. (1) $\left[\mathrm{PrSO}_{3} \mathrm{HMIm} \mathrm{HSO}_{4}\right.$, (2) MIL-100(Fe), (3-7) X-ILs@MIL-100(Fe) $(X=0.7,0.9,1.1,1.3,1.5)$, the following conditions were used: catalyst, $0.05 \mathrm{~g}$; model oil, $10 \mathrm{~mL}$; acetonitrile, $10 \mathrm{~mL} ; \mathrm{H}_{2} \mathrm{O}_{2}, 28$ $\mu \mathrm{L} ; t, 180 \mathrm{~min} ; \mathrm{T}, 60^{\circ} \mathrm{C}$. 
3.5.2 Effects of catalyst dosage on oxidative desulfurization. The effects of catalyst dosage on the DBT oxidation were studied systematically. As shown in Fig. 5, the DBT removal was enhanced dramatically with the increasing catalyst usage from $0.03 \mathrm{~g}$ to $0.05 \mathrm{~g}$, which can be attributed to the increase of the total amount of the catalytic active sites. Apparently, $0.05 \mathrm{~g}$ of catalyst had offered enough catalytic active sites to the conversion of DBT. However, the removal of DBT was decreased with the increasing catalyst usage from $0.05 \mathrm{~g}$ to $0.06 \mathrm{~g}$. It may be that more catalysts would promote self-decomposition of $\mathrm{H}_{2} \mathrm{O}_{2}$, generating oxygen and water, which was not only detrimental to the progress of the oxidation reaction, ${ }^{\mathbf{1 1}}$ but also cause waste of the catalysts. So, the optimal catalyst dosage was $0.05 \mathrm{~g}$.

3.5.3 Effects of the $\mathrm{H}_{2} \mathrm{O}_{2} /$ DBT molar ratios on oxidative desulfurization. To investigate the influence of the oxidant dosage, the experiment was carried out under various $\mathrm{H}_{2} \mathrm{O}_{2}$ / $\operatorname{DBT}(\mathrm{O} / \mathrm{S})$ molar ratios at $60^{\circ} \mathrm{C}$. As shown in Fig. 6, the removal of DBT increased with the increase of the $\mathrm{H}_{2} \mathrm{O}_{2}$ dosage $(\mathrm{O} / \mathrm{S} \leq$ 25), which can be attributed to the increasing production quantity of the catalytic activity species. When $\mathrm{O} / \mathrm{S}=25$, the sulphur removal was $99.31 \%$. However, when a higher amount of $\mathrm{H}_{2} \mathrm{O}_{2}$ was added, the sulphur removal decreased. On the one hand, this confirmed that water had a negative effect on the desulfurization as the amount of the introduced water increased with the increasing amount of hydrogen peroxide. ${ }^{9,38}$ On the other hand, excess $\mathrm{H}_{2} \mathrm{O}_{2}$ enhanced the hydrogen bond between the catalyst particles in the acetonitrile phase, leading to transfer of the agglomerated catalyst into the oil phase, and thus its less availability for ODS which consequently resulted in lower desulfurization rate. ${ }^{39,40}$

3.5.4 Removal of different sulphur substrates. To investigate the effects of $\left[\mathrm{PrSO}_{3} \mathrm{HMIm}\right] \mathrm{HSO}_{4} @ \mathrm{MIL}-100(\mathrm{Fe})$ on different sulphur compounds, ODS of DBT, BT and T were carried out under the same conditions. The removal rates of DBT, BT and T were shown in Fig. 7. The desulfurization reactivity followed the order: DBT $>\mathrm{T}>\mathrm{BT}$. The reactivity should

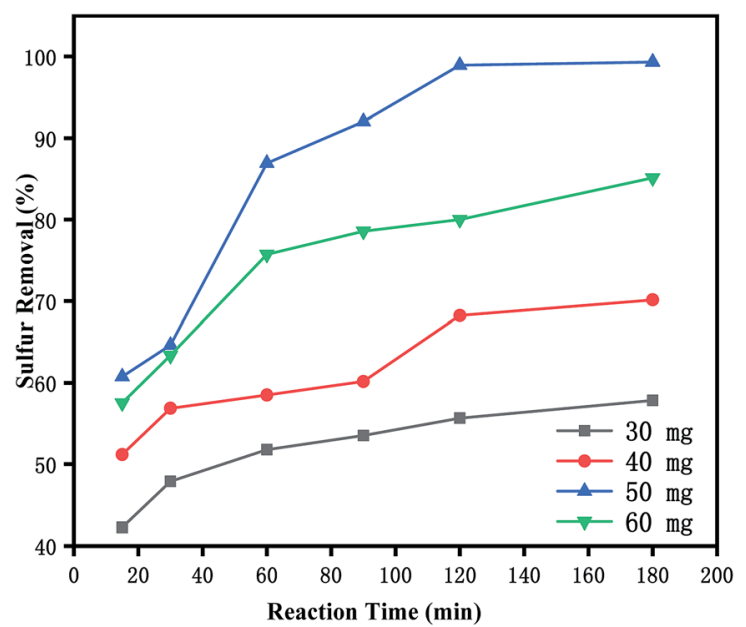

Fig. 5 Effects of catalyst dosage on oxidative desulfurization. (Black) $0.03 \mathrm{~g}$, (red) $0.04 \mathrm{~g}$, (blue) $0.05 \mathrm{~g}$, and (green) $0.06 \mathrm{~g}$. The experiments were conducted under the following conditions: model oil, $10 \mathrm{~mL}$; acetonitrile, $10 \mathrm{~mL} ; \mathrm{H}_{2} \mathrm{O}_{2}, 28 \mu \mathrm{L} ; t, 180 \mathrm{~min} ; \mathrm{T}, 60{ }^{\circ} \mathrm{C}$.

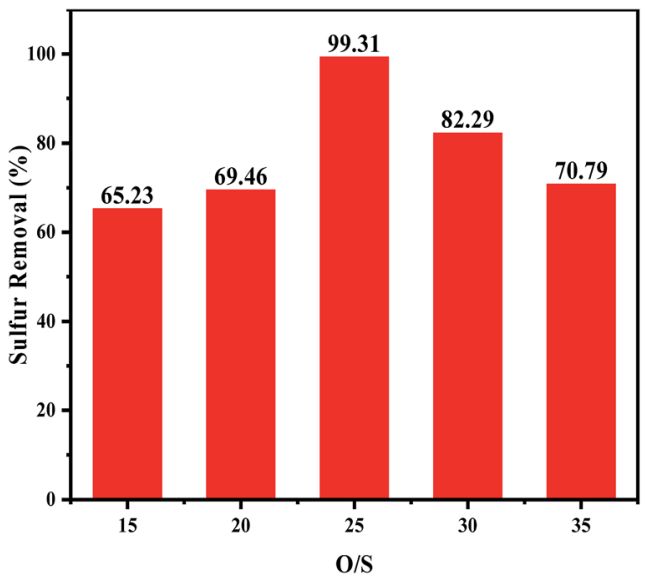

Fig. 6 Effects of $\mathrm{H}_{2} \mathrm{O}_{2} / \mathrm{DBT}$ ratio on oxidative desulfurization. The experiments were conducted under the following conditions: catalyst, $0.05 \mathrm{~g}$; model oil, $10 \mathrm{~mL}$; acetonitrile, $10 \mathrm{~mL}$;, $180 \mathrm{~min} ; \mathrm{T}, 60^{\circ} \mathrm{C}$.

follow the order of the electron density because the removal of sulphur substrates is mainly affected by the electron density on the sulphur atom. ${ }^{41}$ The unusual lowest reactivity of BT can be attributed to the steric hindrance. These results suggested that the reactivity order was affected by the simultaneous effects of the electron density on the sulphur atom and the steric hindrance of the sulphur compounds in this ODS system. Similar results were present in Lv's studies, ${ }^{\mathbf{4 2 , 4 3}}$ they found that sulphur removal selectivity also followed the order of DBT $>$ BT in their ionic liquids extraction coupled with oxidation desulfurization systems (ECODS), and the catalytic activity of DBT removal could reach $98 \%$ at $30{ }^{\circ} \mathrm{C}$ in $3 \mathrm{~h}$.

3.5.5 Recycling of catalysts. The catalysts were separated by centrifugation and dried under vacuum at $353 \mathrm{~K}$ for $12 \mathrm{~h}$ for regeneration. The reutilization for the removal of DBT was performed maintaining the same experimental conditions for each cycle. As is shown in Fig. 8, the catalytic performance of the catalyst decreased to $70 \%$ after five cycles, while the sulphur

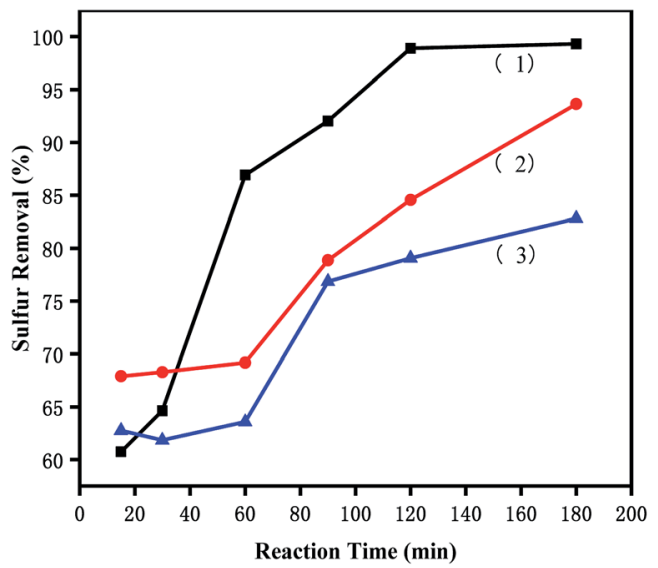

Fig. 7 Effects of different sulphur substrates on oxidative desulfurization. (1) DBT, (2) T, and (3) BT. The experiments were conducted under the following conditions: catalyst, $0.05 \mathrm{~g}$; model oil, $10 \mathrm{~mL}$; acetonitrile, $10 \mathrm{~mL} ; \mathrm{H}_{2} \mathrm{O}_{2}, 28 \mu \mathrm{L} ; t, 180 \mathrm{~min} ; \mathrm{T}, 60^{\circ} \mathrm{C}$. 


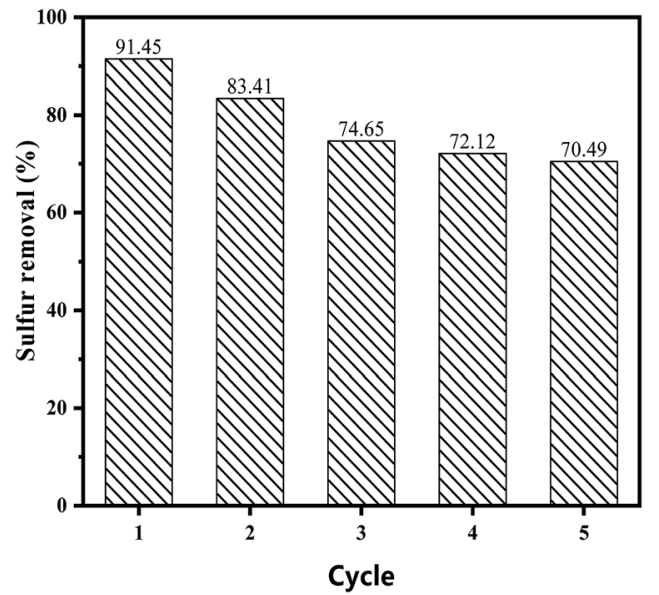

Fig. 8 Recycling of the catalyst on the sulphur removal in the reaction system.

removal in the ECODS systems could remain above $85 \%$ after recycling six times in Lv's studies. ${ }^{42,43}$ The rapid decrease could mainly be attributed to the partial loss of the ionic liquid during the reaction. This show that the carrier with the proper pore structure had a great influence on the catalytic oxidative desulfurization performance.

3.5.6 Proposed mechanism of coupled oxidation extraction desulfurization. Several studies have shown that high desulfurization rate can be achieved with $\mathrm{H}_{2} \mathrm{O}_{2}$ or molecular oxygen as oxidants and different kinds of ionic liquids as catalysts or extractants. In this paper, a coupled oxidation extraction desulfurization mechanism is proposed according to these studies. $^{42-46}$ As seen in Scheme 1, take DBT as an example, firstly, some kinds of radicals (mainly, $\left.\mathrm{HO}_{2}{ }^{\cdot}\right)^{47-49}$ could be produced by $\mathrm{H}_{2} \mathrm{O}_{2}$ with the acidic $\left[\mathrm{PrSO}_{3} \mathrm{HMIm}\right] \mathrm{HSO}_{4}$ and the Brønsted acid sites in MIL-100(Fe) as the catalysts. DBT was then oxidized to the corresponding sulfones by these radicals. Due to their high polarity, the sulfones could be easily removed from the model oil phase by a polar extractant, such as

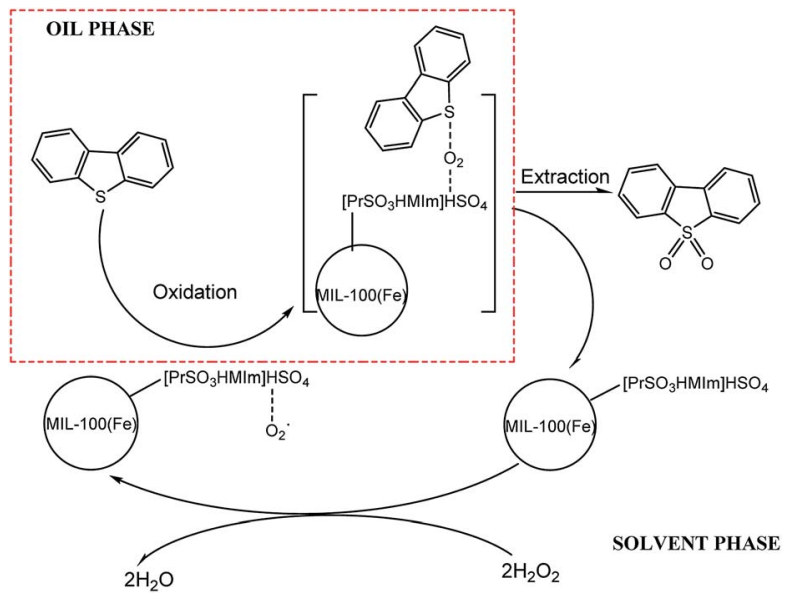

Scheme 1 Proposed mechanism of coupled oxidation extraction desulfurization. acetonitrile in this study. The sulphur-free fuel was then ob-

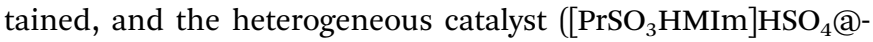
MIL-100(Fe)) could be recycled by static settlement or centrifugation.

\section{Conclusions}

In summary, $\left[\mathrm{PrSO}_{3} \mathrm{HMIm}\right] \mathrm{HSO}_{4}$ immobilized in MIL-100(Fe) was successfully synthesized through wet-impregnation. The XRD, FT-IR, EA and $\mathrm{N}_{2}$ adsorption-desorption indicated that the ILs@MIL-100(Fe) samples remained in the mesoporous structure of MIL-100(Fe). The $\left[\mathrm{PrSO}_{3} \mathrm{HMIm}\right] \mathrm{HSO}_{4} @ \mathrm{MIL}-100(\mathrm{Fe})$ catalysts displayed significantly higher catalytic performance than $\left[\mathrm{PrSO}_{3} \mathrm{HMIm}\right] \mathrm{HSO}_{4}$ for the oxidative desulfurization of DBT. In the experimental system, the effects of different ILs loading, catalyst dosage, $\mathrm{O} / \mathrm{S}$ ratio, and different sulphur substrates on the desulfurization rate were investigated, and the optimum reaction conditions were determined. The 1.1$\left[\mathrm{PrSO}_{3} \mathrm{HMIm}\right] \mathrm{HSO}_{4} @ M I L-100(\mathrm{Fe})$ sample had the highest oxidative desulfurization efficiency, by which, the sulphur removal of DBT reached $99.3 \%$.

\section{Conflicts of interest}

There are no conflicts to declare.

\section{Acknowledgements}

This research was funded by National Natural Science Foundation of China (Grant No. 21676099), and the Fundamental Research Funds for the Central Universities, South China University of Technology.

\section{Notes and references}

1 J. Wu, Y. Gao, W. Zhang, Y. Tan, A. Tang, Y. Men and B. Tang, Appl. Organomet. Chem., 2015, 29, 96-100.

2 D. Bokare and W. Choi, J. Hazard. Mater., 2016, 304, 313-319.

3 A. Stanislaus, A. Marafi and M. S. Rana, Catal. Today, 2010, 153, 1-68.

4 W. Jiang, W. Zhu, Y. Chang, Y. Chao, S. Yin, H. Liu, F. Zhu and H. Li, Chem. Eng. J., 2014, 250, 48-54.

5 C. Li, D. Li, S. Zou, Z. Li, J. Yin, A. Wang, Y. Cui, Z. Yao and Q. Zhao, Green Chem., 2013, 15, 2793-2799.

6 W. Ding, W. Zhu, J. Xiong, L. Yang, A. Wei, M. Zhang and H. Li, Chem. Eng. J., 2015, 266, 213-221.

7 U. Domanska and M. Wlazlo, Fuel, 2014, 134, 114-125.

8 P. S. Kulkarni and C. A. M. Afonso, Green Chem., 2010, 12, 1139-1149.

9 H. Liu, S. Bao, Z. Cai, T. Xu, N. Li, L. Wang, H. Chen, W. Lu and W. Chen, Chem. Eng. J., 2017, 317, 1092-1098.

10 Z. Klimont, S. J. Smith and J. Cofala, Environ. Res. Lett., 2013, 8, 014003.

11 B. Jiang, H. Yang, L. Zhang, R. Zhang, Y. Sun and Y. Huang, Chem. Eng. J., 2016, 283, 89-96.

12 B. Rodriguez-Cabo, H. Rodriguez, E. Rodil, A. Arce and A. Soto, Fuel, 2014, 117, 882-889. 
13 J. Xiong, W. Zhu, H. Li, Y. Xu, W. Jiang, S. Xun, H. Liu and Z. Zhao, AIChE J., 2013, 59, 4696-4704.

14 V. C. Srivastava, $R S C$ Adv., 2012, 2, 759-783.

15 C. Dai, J. Zhang, C. Huang and Z. Lei, Chem. Rev., 2017, 117, 6929-6983.

16 L. Li, J. Zhang, C. Shen, Y. Wang and G. Luo, Fuel, 2016, 167, 9-16.

17 H. Jin, Y. Li, X. Liu, Y. Ban, Y. Peng, W. Jiao and W. Yang, Chem. Eng. Sci., 2015, 124, 170-178.

18 W. Jiang, W. Zhu, H. Li, X. Wang, S. Yin, Y. Chang and H. Li, Fuel, 2015, 140, 590-596.

19 Y. Nie, Y. Dong, L. Bai, H. Dong and X. Zhang, Fuel, 2013, 103, 997-1002.

20 C. Chen, Z. Wu, Y. Que, B. Li, Q. Guo, Z. Li, L. Wang, H. Wan and G. Guan, RSC Adv., 2016, 6, 54119-54128.

21 H. Wan, C. Chen, Z. Wu, Y. Que, Y. Feng, W. Wang, L. Wang, G. Guan and X. Liu, ChemcatChem, 2015, 7, 441-449.

22 M. Han, Z. Gu, C. Chen, Z. Wu, Y. Que, Q. Wang, H. Wan and G. Guan, $R S C A d v .$, 2016, 6, 37110-37117.

23 J. Wang, D. Xie, Z. Zhang, Q. Yang, H. Xing, Y. Yang, Q. Ren and Z. Bao, AIChE J., 2017, 63, 2165-2175.

24 F. P. Kinik, A. Uzun and S. Keskin, ChemSusChem, 2017, 10, 2842-2863.

25 N. M. Mahmoodi, J. Abdi, M. Oveisi, M. A. Asli and M. Vossoughi, Mater. Res. Bull., 2018, 100, 357-366.

26 S. Huang, K. Yang, X. Liu, H. Pan, H. Zhang and S. Yang, RSC Adv., 2017, 7, 5621-5627.

27 Z. Chen, B. Xu, X. Wang, L. Zhang, X. Yang and C. Li, Catal. Commun., 2017, 102, 17-20.

28 S. D. Taherzade, J. Soleimannejad and A. Tarlani, Nanomaterials, 2017, 7, 215.

29 D. Wang, Y. Pan, L. Xu and Z. Li, J. Catal., 2018, 361, 248254.

30 N. U. Qadir, S. A. M. Said, R. B. Mansour, K. Mezghani and A. Ul-Hamid, Dalton Trans., 2016, 45, 15621-15633.

31 J. Cai, X. Wang, Y. Zhou, L. Jiang and C. Wang, Phys. Chem. Chem. Phys., 2016, 18, 10864-10867.

32 Y. Kong, X. Cheng, H. An, X. Zhao and Y. Wang, Chin. J. Chem. Eng., 2018, 26, 330-336.
33 F. Zhang, J. Shi, Y. Jin, Y. Fu, Y. Zhong and W. Zhu, Chem. Eng. J., 2015, 259, 183-190.

34 S. Abednatanzi, A. Abbasi and M. Masteri-Farahani, Catal. Commun., 2017, 96, 6-10.

35 L. Zhang, S. Wu, Y. Liu, F. Wang, X. Han and H. Shang, Appl. Organomet. Chem., 2016, 30, 684-690.

36 J. Xiong, W. Zhu, W. Ding, L. Yang, Y. Chao, H. Li, F. Zhu and H. Li, Ind. Eng. Chem. Res., 2014, 53, 19895-19904.

37 F. Zhang, Y. Jin, J. Shi, Y. Zhong, W. Zhu and M. S. El-Shall, Chem. Eng. J., 2015, 269, 236-244.

38 X. Shi, M. Sun, J. Fan, P. Wang, W. Ma and J. Wei, Appl. Organomet. Chem., 2015, 29, 633-637.

39 H. Azimzadeh, A. Akbari and M. R. Omidkhah, Chem. Eng. J., 2017, 320, 189-200.

40 L. Lu, S. Cheng, J. Gao, G. Gao and M. He, Energy Fuels, 2007, 21, 383-384.

41 M. Zhang, W. Zhu, S. Xun, H. Li, Q. Gu, Z. Zhao and Q. Wang, Chem. Eng. J., 2013, 220, 328-336.

42 H. Lv, W. Ren, H. Wang, Y. Wang, W. Chen and Z. Suo, Appl. Catal., A, 2013, 453, 376-382.

43 H. Lv, C. Deng, W. Ren and X. Yang, Fuel Process. Technol., 2014, 119, 87-91.

44 C. Li, Z. Jiang, J. Gao, Y. Yang, S. Wang, F. Tian, F. Sun, X. Sun, P. Ying and C. Han, Chem.-Eur. J., 2004, 10, 22772280.

45 M. Craven, D. Xiao, C. Olsen, E. Kozhevnikova, F. Blanc, A. Steiner and I. V. Kozhevnikov, Appl. Catal., B, 2018, 231, 82-91.

46 S. Gao, J. Lia, X. Chen, A. A. Abdeltawab, S. M. Yakout and G. Yu, Fuel, 2018, 224, 545-551.

47 W. Zhu, C. Wang, H. Li, P. Wu, S. Xun, W. Jiang, Z. Chen, Z. Zhao and H. Li, Green Chem., 2015, 17, 2464-2472.

48 P. Wu, W. Zhu, Y. Chao, J. Zhang, P. Zhang, H. Zhu, C. Li, Z. Chen, H. Li and S. Dai, Chem. Commun., 2016, 52, 144147.

49 W. Jiang, H. Jia, H. Li, L. Zhu, R. Tao, W. Zhu, H. Li and S. Dai, Green Chem., 2019, 21, 3074-3080. 